\title{
Effect of Titanium Dioxide on Some Mechanical, Thermal, and Surface Properties of Wood-Plastic Nanocomposites
}

\begin{abstract}
Alperen Kaymakci *
The effects of $\mathrm{TiO}_{2}$ (titanium dioxide) loading were evaluated relative to mechanical, thermal, and surface properties of the wood-plastic nanocomposites (WPNs). Pine wood flour, mixed with maleic anhydride polypropylene (MAPP), $\mathrm{TiO}_{2}$ nanoparticles (0 wt \%, $1 \mathrm{wt} \%, 2 \mathrm{wt} \%, 3 \mathrm{wt} \%$, $4 \mathrm{wt} \%$, and $5 \mathrm{wt} \%$ ), and polypropylene, was compounded in a twin screw co-rotating extruder. The mass ratio of the wood flour to polypropylene (PP) was 50/50 (w/w) in all compounds. Test specimens were produced using injection molding machine from the pellets. Flexural and tensile properties, thermogravimetric analysis, surface roughness, wettability, and morphology of the manufactured nanocomposites were evaluated. Flexural and tensile properties of the wood-plastic nanocomposites increased with the increasing content of the $\mathrm{TiO}_{2}$. The surface roughness of the wood-plastic nanocomposites was reduced by increasing the content of $\mathrm{TiO}_{2}$. Increasing the loading of $\mathrm{TiO}_{2}$ increased the amount of residual ash and thermal stability.
\end{abstract}

Keywords: Wood; Nanocomposites; $\mathrm{TiO}_{2}$; Mechanical properties; SEM

Contact information: Assistant Professor, Kastamonu University, Faculty of Forestry, Department of Forest Industry Engineering, Kastamonu, 37150, Turkey;

*Corresponding author: akaymakci@kastamonu.edu.tr

\section{INTRODUCTION}

Composite materials are prepared for a specific purpose, formed by the combination of two or more materials at a macroscopic level, with different morphological, physical, and mechanical properties. The advantage of composites is that they can exhibit new and different properties than the individual raw materials. Composite materials consist of a matrix and reinforcing agent components. The most frequently used reinforcing components are calcium carbonate, glass wool, talc, powder ceramics, and mica. However, these inorganic fillers cause machine wear, and they are costly (Gan 2009; Turku et al. 2017, 2018). The idea of utilizing lignocellulosic fibers as the reinforcing material and filler has emerged in the composite material industry. The lignocellulosic fillers used in composite production reduce the total production costs and provide significant performance improvements. Lignocellulosic materials such as wheat stalk, barley stalk, wood flour and fiber, carpenter's waste, hemp stalks, kenaf, and sunflower stalks have been utilized in the production of wood-plastic composites. These materials reduce the amount of polymer used. Wood-polymer composites (WPCs) are innovative hybrid materials and replace many traditional product applications due to their 3-D moldability, durability, and weatherability (Krause 2015). Wood-plastic composites are used in many areas such as flooring material, automobile panels, fences, garden furniture, and exterior façades (Zhang et al. 2010; Bajwa et al. 2011; Bazant et al. 2014; Ayrilmis et al. 2015; Homkhiew et al. 
2014; Gardner et al. 2017; Ratanawilai and Taneerat 2018). Despite the many advantages of wood-plastic composites, some shortcomings (i.e., relatively low modulus, low impact resistance, and creep performance) have led researchers to use various compatibilizers or nanoparticles that serve as interfacial adhesives to improve the performance of woodplastic composites. Nano-sized reinforcing materials have the potential to provide significant performance improvements in wood-plastic composites due to their high specific properties. Thus, wood-plastic nanocomposites (WPNs) are expected to become high performance and value added products for end use with advantages such as high modulus value, high shock resistance, and thermal stability. Nanocomposites are materials formed by the dispersion of nanometer-sized particles within a matrix (Chen et al. 2007; Klyosov 2007; Lei et al. 2007; Ghasemi and Kord 2009; Kasraei and Azarsina 2012; Beigloo et al. 2017; Nikmatin et al. 2017; Asikuzun and Kaymakci 2018). Thus, WPNs are obtained by mixing nano material, plastic, and lignocellulosic fillers with conventional wood-plastic composite methods. Many nanomaterials such as carbon nanotube, boron nitride, clay, $\mathrm{SiO}_{2}$, and $\mathrm{TiO}_{2}$ are used in the production of WPNs. In particular, $\mathrm{TiO}_{2}$ has received numerous applications due to its strong oxidizing power, chemical inertness, nontoxic, low cost, high refractive index and other advantageous surface properties. Also, the surface of $\mathrm{TiO}_{2}$ is capable of absorbing, decomposing or reacting (oxidizing / reducing) a wide variety of inorganic and organic molecules and atoms under certain conditions. The most important among them is the $\mathrm{H}_{2} \mathrm{O}$ dissociative or nondissociatve adsorption behavior on $\mathrm{TiO}_{2}$, which determines $\mathrm{TiO}_{2}$ wetting and dispersing abilities in aqueous or non-aqueous medium and other surface properties (Lin 2006). However, there is a need for information on the effectiveness of these materials in the composite structure. The performance of nanoparticles with lignocellulosic materials and polymers needs further examination. This study investigated the effect of $\mathrm{TiO}_{2}$ loading on some mechanical, thermal, and surface properties of wood-plastic nanocomposites.

\section{EXPERIMENTAL}

\section{Materials}

Yellow pine (Pinus sylvestris) wood flour was used as a lignocellulosic filler. The flour was purchased from a wood-plastic composite deck manufacturer (Semadeck, Tekirdag, Turkey). The wood flour (sapwood part) passing through a 40-mesh screen was retained on an 80-mesh screen. Polypropylene (PP) with a density of $0.9 \mathrm{~g} / \mathrm{cm}^{3}$ was purchased from Borealis Incorp in Austria. It has a melting point of $170{ }^{\circ} \mathrm{C}$ and a melt flow index of $2.5 \mathrm{~g} / 10 \mathrm{~min}$ at $230{ }^{\circ} \mathrm{C}$. To eliminate the incompatibility between the polypropylene and the pine wood flour and to increase the bonding, maleic anhydride polypropylene (MAPP) (Optim-425; melt flow index about $120 \mathrm{~g} / 10 \mathrm{~min}$ at $190{ }^{\circ} \mathrm{C}$ and a density $0.91 \mathrm{~g} / \mathrm{cm}^{3}$ Pluss Polymers Pvt. Ltd., Gurugram, India) was used. As the reinforcing filler, titanium dioxide $\left(\mathrm{TiO}_{2}\right)$ (Grafen Company, Ankara, Turkey) was used. Some characteristics of the reinforcing fillers are given in Table 1.

Polypropylene, pine wood flour (WF), $\mathrm{TiO}_{2}$, and the compatibilizer maleic acid grafted polypropylene (MAPP) were used as purchased from the manufacturer. The readymade wood flour was oven-dried at $103{ }^{\circ} \mathrm{C} \pm 2{ }^{\circ} \mathrm{C}$ for $24 \mathrm{~h}$. Drying the wood flour was important because moisture in lignocellulosic fillers causes bubbles to form during the extrusion and injection molding processes, leading to performance loss. 
Table 1. Specifications of the $\mathrm{TiO}_{2}$

\begin{tabular}{|c|c|}
\hline Property & $\mathrm{TiO}_{2}$ \\
\hline Appearance & White powder \\
\hline Average particle size & $10 \mathrm{~nm}$ to $25 \mathrm{~nm}$ \\
\hline Purity & $>99.5 \%$ \\
\hline Surface area & $>50 \mathrm{~m}^{2} / \mathrm{g}$ \\
\hline
\end{tabular}

\section{Production of the Wood-plastic Nanocomposites}

The production of WPNs was carried out in two phases: pellet production and nanocomposite production. In the first phase, small granules (pellets) were produced, while in the second phase samples were produced by injection molding. Prior to the production, the wood flour was dried until the moisture was reduced to below $1 \%$. The dried wood flour was melted in the extruder (Aysa Machine, Istanbul, Turkey) by premixing it with the polypropylene (PP), $\mathrm{TiO}_{2}$, and MAPP according to the production prescription (Table 2 ) and then pushed into the die with the screw in the double screw extruder (temperature of $185^{\circ} \mathrm{C}$ to $200{ }^{\circ} \mathrm{C}$ ). The molten material that exited through the die in the extruder end was cooled with cold water and left to dry. Composite samples in the shape of fine rods dried at $80^{\circ} \mathrm{C}$ for $3 \mathrm{~h}$ were made into pellets via a plastic crusher (ZHL-SA, TSP Machine, Tekirdag, Turkey).

The pellets were oven-dried until reaching a content of $1 \%$ to $2 \%$ moisture before the injection molding process. The dried pellets were made into a test sample in an injection molding machine (TSPX 60; TSP Machine, Tekirdag, Turkey) operating at a screw speed of $40 \mathrm{rpm}$ and a temperature of $185^{\circ} \mathrm{C}$ to $200{ }^{\circ} \mathrm{C}$. The injection pressure was set to $5 \mathrm{MPa}$ to $6 \mathrm{MPa}$, the injection speed was $80 \mathrm{~mm} / \mathrm{s}$, and the cooling rate was $30 \mathrm{~s}$. The specimens were stored under controlled conditions $\left(50 \%\right.$ relative humidity and $\left.23{ }^{\circ} \mathrm{C}\right)$ for at least 24 $\mathrm{h}$ prior to testing.

Table 2. Composition of the Evaluated Formulations

\begin{tabular}{|c|c|c|c|c|}
\hline $\mathrm{ID}$ & $\mathrm{WF}(\mathrm{wt} \%)$ & $\mathrm{TiO}_{2}(\mathrm{PhC})^{\star}$ & $\mathrm{PP}(\mathrm{wt} \%)$ & $\mathrm{MAPP}(\mathrm{wt} \%)$ \\
\hline $\mathrm{A}$ & 50 & 0 & 50 & 3 \\
\hline $\mathrm{B}$ & 50 & 1 & 50 & 3 \\
\hline $\mathrm{C}$ & 50 & 2 & 50 & 3 \\
\hline $\mathrm{D}$ & 50 & 3 & 50 & 3 \\
\hline $\mathrm{E}$ & 50 & 4 & 50 & 3 \\
\hline $\mathrm{F}$ & 50 & 5 & 50 & 3 \\
\hline
\end{tabular}

${ }^{*}$ Per hundred compounds

\section{Methods}

Mechanical properties

The flexural tests and tensile tests were conducted according to the ISO 178 (2010) and the ISO 527-1 (2012), respectively, using a Lloyd universal testing machine (Model LS 100, Bognor Regis, UK). The tests were performed at a crosshead speed of $5 \mathrm{~mm} / \mathrm{min}$. Seven replicates were tested for both the flexural and tensile strength measurements.

\section{Thermogravimetric analysis}

A Hitachi STA 7300 (Tokyo, Japan) apparatus was used for thermogravimetric analysis (TGA). Nitrogen gas was used at a flow rate of $20 \mathrm{~mL} / \mathrm{min}$; samples were in quantities of $9 \mathrm{mg}$ to $10 \mathrm{mg}$. 3 samples were used for thermogravimetric analysis (TGA). 
The temperature during this test was increased from room temperature to $500{ }^{\circ} \mathrm{C}$ with a heating rate of $10^{\circ} \mathrm{C} / \mathrm{min}$. The thermal degradation temperatures and the amount of waste were noted.

\section{Wettability and surface roughness measurements}

A KSV Cam-101 (Helsinki, Finland) was used to determine the contact angle of the wood-plastic nanocomposite surface. A drop of distilled water was placed on the composite surface, and the contact angle was determined using the KSV software package. The contact angles were measured up to $180 \mathrm{~s}$ every $3 \mathrm{~s}$. The contact angle was measured for at least five specimens of each nanocomposite group.

For the surface roughness test, a total of 48 specimens were taken as 8 samples from each group of wood-plastic nanocomposites. Surface roughness tests were performed on the Zeiss Handysurf E-35A stylus type profilometer (Oberkochen, Germany) according to ISO 4287 (1997). Two roughness parameters, average roughness $\left(R_{\mathrm{a}}\right)$ and mean peakto-valley height $\left(R_{\mathrm{z}}\right)$, were used to evaluate the surface roughness of the wood-plastic nanocomposites.

Scanning electron microscope (SEM) analysis

The SEM analyses of wood-plastic nanocomposite materials were performed on an FEI Quanta-FEG 250 microscope (Hillsboro, OR, USA). The specimens were left in liquid nitrogen for a period and then fractured to obtain a clean fractured surface prior to the analysis. To prevent any possible reflections that may occur on the surfaces of the samples, the fractured surfaces were coated with gold dust for $120 \mathrm{~s}$ at $10 \mathrm{~mA}$.

\section{Statistical analysis}

IBM SPSS Statistics 23 statistical software (New York, USA) was used for statistical analysis. An analysis of variance (ANOVA) was conducted ( $p<0.05)$ to evaluate the effect of the $\mathrm{TiO}_{2}$ content on the mechanical, thermal, and surface properties of WPNs. Significant differences among the average values of the wood-plastic nanocomposite types were determined using Duncan's multiple range tests.

\section{RESULTS AND DISCUSSION}

\section{Mechanical Properties}

The flexural and tensile properties of $\mathrm{TiO}_{2}$ reinforced wood-plastic nanocomposites are shown in Table 3. With $\mathrm{TiO}_{2}$ loading, the flexural properties and tensile properties of WPNs improved. The samples containing $\mathrm{TiO}_{2}$ exhibited a more rigid structure than the groups without $\mathrm{TiO}_{2}$.

The increase in the flexural modulus of the wood-plastic nanocomposites was higher than the increase in the flexural strength. For example, the flexural strength of the nanocomposite group with $5 \% \mathrm{TiO}_{2}$ was increased by $8.9 \%$, while the flexural modulus of the group increased by $14.7 \%$. The specimen types presenting significant differences with further groups according to Duncan's multiple-range tests are shown by superscript letters in Table 3. The flexural strength of wood-plastic nanocomposites was significantly affected by the amount of $\mathrm{TiO}_{2}$. 
Table 3. Mechanical Properties of the WPNs Reinforced with $\mathrm{TiO}_{2}$

\begin{tabular}{|c|c|c|c|c|c|}
\hline $\mathrm{ID}^{1}$ & $\begin{array}{c}\text { Flexural } \\
\text { Strength } \\
\left(\mathrm{N} / \mathrm{mm}^{2}\right)\end{array}$ & $\begin{array}{c}\text { Flexural } \\
\text { Modulus } \\
\left(\mathrm{N} / \mathrm{mm}^{2}\right)\end{array}$ & $\begin{array}{c}\text { Tensile } \\
\text { Strength } \\
\left(\mathrm{N} / \mathrm{mm}^{2}\right)\end{array}$ & $\begin{array}{c}\text { Tensile } \\
\text { modulus } \\
\left(\mathrm{N} / \mathrm{mm}^{2}\right)\end{array}$ & $\begin{array}{c}\text { Elongation at } \\
\text { Break } \\
(\%)\end{array}$ \\
\hline $\mathrm{A}$ & $59.5(0.9) \mathrm{a}$ & $4904(336) \mathrm{ns}^{2}$ & $18.1(2.3) \mathrm{a}$ & $1266(95) \mathrm{a}$ & $6.1(0.7) \mathrm{a}$ \\
\hline $\mathrm{B}$ & $60.5(1.5) \mathrm{a}$ & $4996(259) \mathrm{ns}$ & $23.0(2.1) \mathrm{b}$ & $1292(80) \mathrm{a}$ & $6.1(0.9) \mathrm{a}$ \\
\hline $\mathrm{C}$ & $61.5(3.0) \mathrm{a}$ & $5177(796) \mathrm{ns}$ & $25.3(1.3) \mathrm{c}$ & $1311(80) \mathrm{a}$ & $5.8(0.5) \mathrm{a}$ \\
\hline $\mathrm{D}$ & $61.7(2.3) \mathrm{a}$ & $5279(726) \mathrm{ns}$ & $26.0(0.8) \mathrm{cd}$ & $1411(101) \mathrm{b}$ & $5.8(0.6) \mathrm{a}$ \\
\hline $\mathrm{E}$ & $64.0(2.1) \mathrm{b}$ & $5486(487) \mathrm{ns}$ & $26.2(0.5) \mathrm{cd}$ & $1421(65) \mathrm{b}$ & $4.7(0.6) \mathrm{b}$ \\
\hline $\mathrm{F}$ & $64.8(1.2) \mathrm{b}$ & $5627(570) \mathrm{ns}$ & $27.8(2.2) \mathrm{d}$ & $1545(80) \mathrm{c}$ & $3.9(0.7) \mathrm{c}$ \\
\hline
\end{tabular}

Groups with the same letters in a column showed no statistical difference $(p<0.01)$ between the samples according Duncan's multiple range test; values in parentheses are the standard deviations. ${ }^{1}$ See Table $2,{ }^{2}$ ns: not significant

As shown in Table 3, a maximum flexural strength of $64.8 \mathrm{~N} / \mathrm{mm}^{2}$ was found in the nanocomposite groups containing $5 \% \mathrm{TiO}_{2}$. The minimum flexural strength of $59.5 \mathrm{~N} / \mathrm{mm}^{2}$ was found in control group samples without $\mathrm{TiO}_{2}$. The flexural strength and elasticity modulus increased as the amount of $\mathrm{TiO}_{2}$ in the nanocomposite structure increased. This can be attributed to the positive compatibility among $\mathrm{TiO}_{2}, \mathrm{WF}$, and PP. These results show similarities to previous studies. Hazarika and Maji (2013) investigated the synergistic effect of nano- $\mathrm{TiO}_{2}$ and nanoclay on the ultraviolet degradation and physical properties of wood polymer nanocomposites. According to their results, the incorporation of nanoclay and nano- $\mathrm{TiO}_{2}$ influences the mechanical properties of the wood polymer nanocomposites to a substantial amount. At a constant clay amount ( $3 \mathrm{phr}$ ), the mechanical properties of the wood polymer nanocomposites improve with an increase in $\mathrm{TiO}_{2}$ loading. The polymer chains were fastened in the gallery layers of the nanoclay, limiting the mobility of the polymer chains and stiffening the nanocomposites. This is explained by the positive coalescence between the nanomaterials and the nanocomposite structure (Hazarika and Maji 2013).

The tensile strength, tensile modulus, and elongation at break values of the woodplastic nanocomposites were significantly improved by the incorporation of the $\mathrm{TiO}_{2}$. The tensile strength of wood-plastic nanocomposites increased from $18.1 \mathrm{~N} / \mathrm{mm}^{2}$ to 27.8 $\mathrm{N} / \mathrm{mm}^{2}$ as the $\mathrm{TiO}_{2}$ content increased from $0 \mathrm{wt} \%$ to $5 \mathrm{wt} \%$. The specimen treated with 5 $\mathrm{wt} \% \mathrm{TiO}_{2}$ and $3 \mathrm{wt} \%$ MAPP showed the highest tensile strength values among the other types of wood-plastic nanocomposites. This result was consistent with the observation that the introduction of nano-sized particles into a polymer matrix increased its tensile properties. The improvement is logical because the filler in the $\mathrm{TiO}_{2}$ form can carry more tensile load. Furthermore, the $\mathrm{TiO}_{2}$ is much stiffer than the polymer matrix, and as a result it adds stiffness to the nanocomposites. The obtained data corresponded with other studies. Deka and Maji (2011) investigated the effect of $\mathrm{TiO}_{2}$ and nanoclay on the properties of wood polymer nanocomposites. The study determined that the value of tensile strength increases depending on the increasing content of nanoclay and $\mathrm{TiO}_{2}$. This increase was attributed to improved interfacial adhesion between the polymers by the compatibilizer (Deka and Maji 2011). In another study, Saeed et al. (2009) investigated the characterization of poly(butylene terephthalate) electrospun nanofibers containing $\mathrm{TiO}_{2}$. They determined that the tensile strength of electrospun nanofibers increases based on an increase in the usage ratio of $\mathrm{TiO}_{2}$. In addition, at higher percentages of $\mathrm{TiO}_{2}$ loading (5 phr), the effective agglomeration of the nanoparticles results in decreased mechanical properties (Saeed et al. 2009). The tensile elongation at break values of the wood-plastic 
nanocomposites were significantly improved by the incorporation of the $\mathrm{TiO}_{2}$. The tensile elongation at break value of wood-plastic nanocomposites decreased from $6.1 \%$ to $3.9 \%$ as the $\mathrm{TiO}_{2}$ content increased from $0 \mathrm{wt} \%$ to $5 \mathrm{wt} \%$.

\section{Thermogravimetric Analysis and Scanning Electron Microscopy}

The results of the thermogravimetric analysis (TGA) are presented in Table 4. The thermal stability of WPNs improved with increasing $\mathrm{TiO}_{2}$ loading.

Table 4. Thermogravimetric Analysis of the WPNs Reinforced with $\mathrm{TiO}_{2}$

\begin{tabular}{|c|c|c|c|c|c|}
\hline \multirow{2}{*}{$\mathrm{ID}^{1}$} & $\begin{array}{c}\text { Onset Temperature } \\
\left({ }^{\circ} \mathrm{C}\right)\end{array}$ & \multicolumn{2}{|c|}{ Peak Temperature $\left({ }^{\circ} \mathrm{C}\right)$} & \multirow{2}{*}{$\begin{array}{c}\text { Total Weight Loss } \\
(\%)\end{array}$} & $\begin{array}{c}\text { Residue after } \\
500{ }^{\circ} \mathrm{C}\end{array}$ \\
\cline { 3 - 6 } & 196.8 & 303.4 & 449.5 & 91.7 & $(\%)$ \\
\hline $\mathrm{A}$ & 198.4 & 303.5 & 450 & 91.1 & 8.3 \\
\hline $\mathrm{B}$ & 215.6 & 307 & 451.9 & 90.9 & 8.9 \\
\hline $\mathrm{C}$ & 218.4 & 309.1 & 452.3 & 87.9 & 12.1 \\
\hline $\mathrm{D}$ & 225.6 & 311.2 & 452.4 & 86.7 & 13.3 \\
\hline $\mathrm{E}$ & 227.4 & 311.3 & 453.2 & 77.5 & 22.5 \\
\hline $\mathrm{F}$ & 2 & \multicolumn{4}{|l}{} \\
\hline
\end{tabular}

The maximum onset temperature was $227.2^{\circ} \mathrm{C}$ in the nanocomposite groups containing $5 \% \mathrm{TiO}_{2}$. The minimum onset temperature was $196.8^{\circ} \mathrm{C}$ in the nanocomposite control groups. The total weight loss decreased with an increase in the amount of $\mathrm{TiO}_{2}$ in the nanocomposites. Total weight loss, for instance, decreased from $91.7 \%$ to $77.5 \%$ when $\mathrm{TiO}_{2}$ loading on the wood-plastic nanocomposites increased from $0 \mathrm{wt} \%$ to $5 \mathrm{wt} \%$. The obtained data showed similarities with previous studies. Rahman et al. (2017) investigated the differential scanning calorimetry (DSC) and the TGA of wood polymer nanocomposites. According to their results, the presence of nanoparticles in the lignocellulose matrix results in an increase in the thermal stability of the nanocomposite. Additionally, the results show that the mass loss (\%) decreases with an increase in the amount of nanoparticles in the nanocomposites (Rahman et al. 2017).

\section{Wettability and Surface Roughness}

The average roughness $\left(R_{\mathrm{a}}\right)$ values and mean peak-to-valley height $\left(R_{\mathrm{z}}\right)$ values of the WPNs reinforced with $\mathrm{TiO}_{2}$ are presented in Table 5. The surface roughness values of the WPNs decreased with the addition of $\mathrm{TiO}_{2}$ (Fig. 1). When the surface roughness values of the WPNs were examined, the highest $R_{\mathrm{a}}$ value was found in group A with $3.9 \mu \mathrm{m}$, and the lowest $R_{\text {a value of }} 2.8 \mu \mathrm{m}$ was observed in group F. The surface roughness of the WPNs was reduced by increasing the content of $\mathrm{TiO}_{2}$.

Table 5. Surface Roughness Results of Wood-Plastic Nanocomposites

\begin{tabular}{|c|c|c|}
\hline $\mathrm{ID}^{1}$ & $\boldsymbol{R}_{\mathbf{a}}(\boldsymbol{\mu} \mathbf{m})$ & $\boldsymbol{R}_{\mathbf{z}}(\boldsymbol{\mu m})$ \\
\hline $\mathrm{A}$ & $3.9(0.21)^{*} \mathrm{a}$ & $24.5(1.98) \mathrm{a}$ \\
\hline $\mathrm{B}$ & $3.6(0.08) \mathrm{ab}$ & $22.7(2.07) \mathrm{ab}$ \\
\hline $\mathrm{C}$ & $3.3(0.36) \mathrm{bc}$ & $21.9(3.22) \mathrm{bc}$ \\
\hline $\mathrm{D}$ & $3.01(0.30) \mathrm{cd}$ & $20.7(2.50) \mathrm{bcd}$ \\
\hline $\mathrm{E}$ & $3.01(0.26) \mathrm{d}$ & $19.6(0.61) \mathrm{cd}$ \\
\hline F & $2.8(0.30) \mathrm{d}$ & $18.9(0.38) \mathrm{d}$ \\
\hline
\end{tabular}

* Values in parentheses are standard deviations; ${ }^{1}$ See Table 2 
The higher surface roughness of the WPNs was attributed to the presence of gaps and micro-cracks on their surface (see Fig. 3)

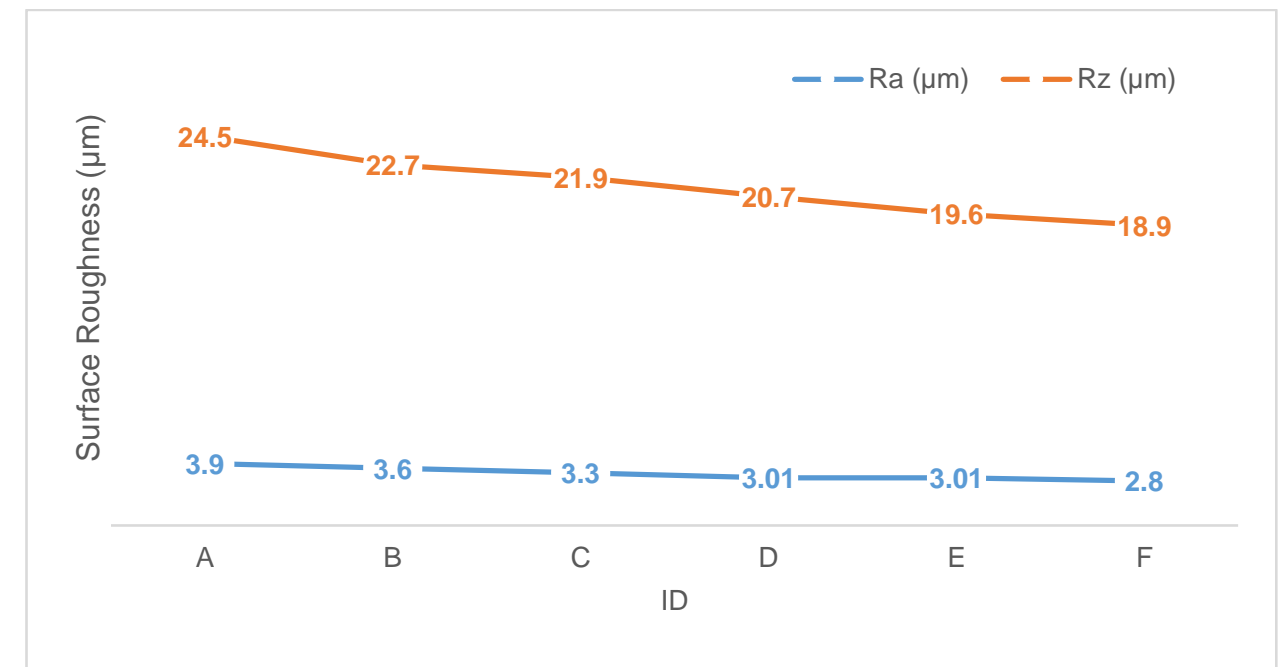

Fig. 1. Effect of $\mathrm{TiO}_{2}$ on surface roughness values of wood plastic nanocomposites

Similar findings were observed for the $R_{\mathrm{z}}$ values. These results show similarities to other studies. Hazarika and Maji (2013) investigated the synergistic effect of nano- $\mathrm{TiO}_{2}$ and nanoclay on the ultraviolet degradation and physical properties of wood polymer nanocomposites; the incorporation of nanoclay and nano- $\mathrm{TiO}_{2}$ influenced the mechanical properties of the wood polymer nanocomposites to a significant amount. Nikmatin et al. (2017) investigated the physical, thermal, and mechanical properties of polypropylene composites filled with rattan nanoparticles. The surface morphology of polypropylene composites improves with the presence of rattan nanoparticles. In addition, the surface morphology of a composite is a key factor that affects the physical, thermal, and mechanical properties of the composites. Liang et al. (2014) investigated the effect of impregnated inorganic nanoparticles on the properties of the kenaf bast fibers. In this work, where the surface roughness is determined by the AFM method, the presence of nanoparticles improves the root mean square surface roughness of the kenaf bast fibers. Means and standard deviations of the WPN wettability values are given in Table 6.

Table 6. Contact Angles Measurements of Wood-Plastic Nanocomposites

\begin{tabular}{|c|c|c|c|c|c|c|c|}
\hline $\mathrm{ID}^{1}$ & $\begin{array}{c}10 \mathrm{~s} \\
\text { Degree }\left({ }^{\circ}\right)\end{array}$ & $\begin{array}{c}30 \mathrm{~s} \\
\text { Degree }\left(^{\circ}\right)\end{array}$ & $\begin{array}{c}60 \mathrm{~s} \\
\text { Degree }\left(^{\circ}\right)\end{array}$ & $\begin{array}{c}90 \mathrm{~s} \\
\text { Degree }\left(^{\circ}\right)\end{array}$ & $\begin{array}{c}120 \mathrm{~s} \\
\text { Degree }\left(^{\circ}\right)\end{array}$ & $\begin{array}{c}150 \mathrm{~s} \\
\text { Degree }\left({ }^{\circ}\right)\end{array}$ & $\begin{array}{c}180 \mathrm{~s} \\
\text { Degree }\left(^{\circ}\right.\end{array}$ \\
\hline $\mathrm{A}$ & 107.9 & 105.7 & 103.8 & 100.6 & 99.6 & 98.8 & 97.2 \\
& $(3.68)$ & $(3.54)$ & $(2.98)$ & $(3.98)$ & $(3.45)$ & $(4.12)$ & $(3.88)$ \\
\hline $\mathrm{B}$ & 105.8 & 104.6 & 103.8 & 101.1 & 99.8 & 97.5 & 95.7 \\
& $(0.87$ & $(1.21)$ & $(1.64)$ & $(2.67)$ & $(2.39)$ & $(3.33)$ & $(2.87)$ \\
\hline $\mathrm{C}$ & 103.0 & 102.8 & 100.6 & 99.3 & 97.7 & 95.4 & 93.7 \\
& $(2.51)$ & $(2.97)$ & $(2.37)$ & $(1.56)$ & $(1.78)$ & $(2.34)$ & $(0.56)$ \\
\hline $\mathrm{D}$ & 101.7 & 100.3 & 99.7 & 97.1 & 95.6 & 93.4 & 90.8 \\
& $(1.91)$ & $(1.63)$ & $(0.89)$ & $(2.35)$ & $(2.78)$ & $(1.87)$ & $(3.63)$ \\
\hline $\mathrm{E}$ & 95.7 & 94.2 & 90.3 & 89.6 & 86.5 & 84.8 & 83.9 \\
& $(0.91)$ & $(1.41)$ & $(3.12)$ & $(3.31)$ & $(4.15)$ & $(1.32)$ & $(2.87)$ \\
\hline $\mathrm{F}$ & 92.1 & 91.6 & 90.4 & 88.9 & 86.3 & 85.4 & 81.6 \\
& $(0.96){ }^{*}$ & $(0.85)$ & $(1.25)$ & $(2.75)$ & $(0.96)$ & $(1.12)$ & $(1.37)$ \\
\hline \multicolumn{7}{|c|}{${ }^{*}$ Values in parentheses are standard deviations; ${ }^{1}$ See Table 2 } \\
\hline
\end{tabular}


The wettability decreased with the increasing $\mathrm{TiO}_{2}$ content. The lowest contact angle was $92.1^{\circ}$ in WPNs containing $5 \% \mathrm{TiO}_{2}$ (group A). The highest contact angle of $107.9^{\circ}$ was observed in group A. The highest contact angle value of $107.9^{\circ}(10 \mathrm{~s})$ was found for samples containing $5 \% \mathrm{TiO}_{2}$. The contact angle of the specimens was significantly affected by increasing the $\mathrm{TiO}_{2}$ content (Fig. 2). The obtained data show similarities with previous studies. Kasraei and Azarsina (2012) investigated the effect of silver nanoparticles on the wettability of methacrylate and silorane-based composites; the addition of silver nanoparticles causes a reduction in the water contact angle of the composites.

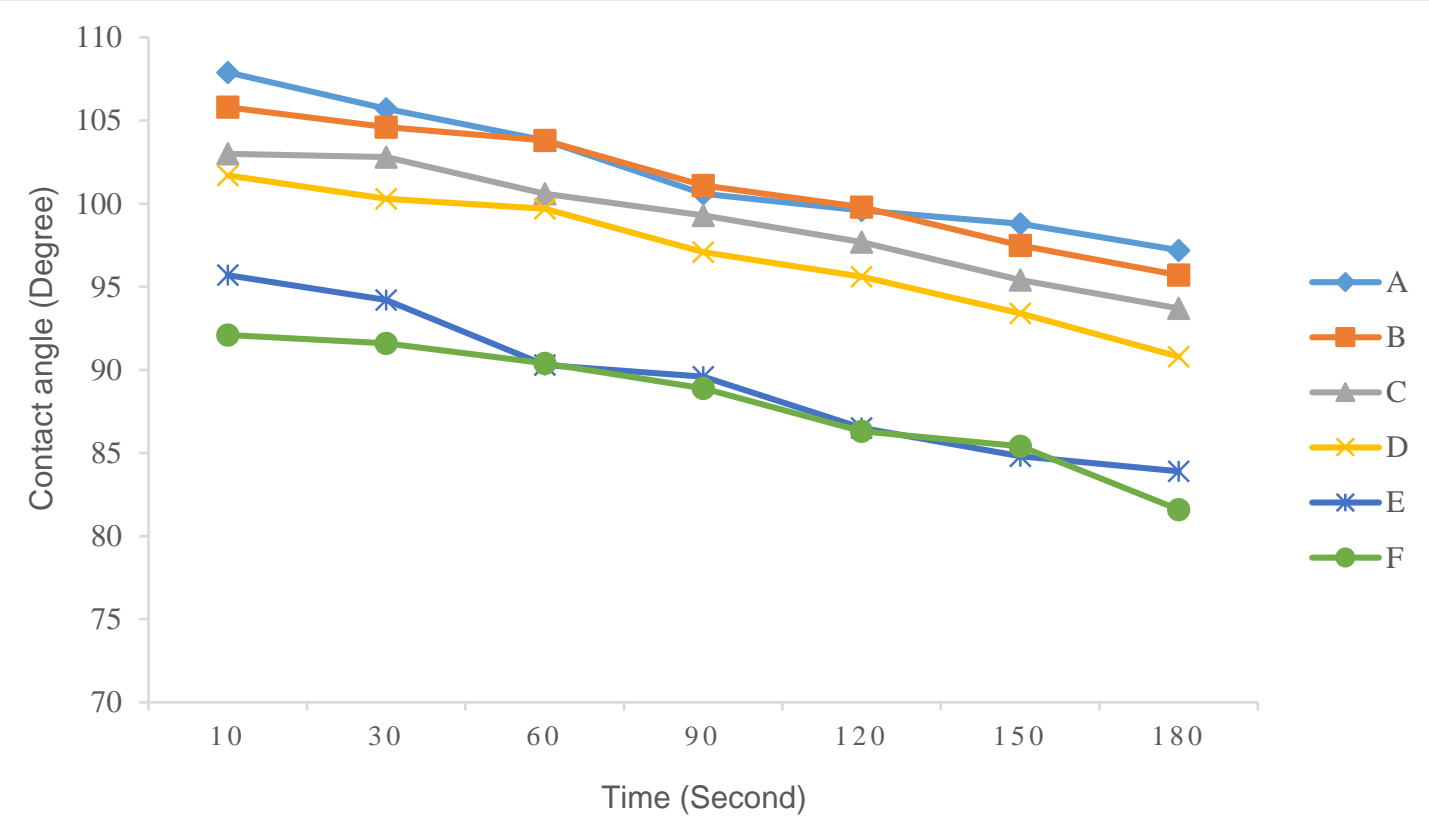

Fig. 2. Effect of $\mathrm{TiO}_{2}$ on contact angle values of wood plastic nanocomposites

\section{Scanning Electron Microscopy (SEM)}

The morphology of the $\mathrm{TiO}_{2}$ reinforced WPNs was studied. SEM micrographs for all groups are shown in Fig. 3. There were no obvious differences between the composites with reinforced and unreinforced groups, but the adhesion was better in the composite reinforced with $\mathrm{TiO}_{2}$.

The improvements in flexural strength, flexural modulus, tensile strength, and tensile modulus of the WPNs with incorporation of $\mathrm{TiO}_{2}$ was supported by SEM. No large gaps between the matrix, wood flour, and $\mathrm{TiO}_{2}$ are shown in the images. The results confirmed the observed enhancement in the physical, mechanical, and thermal performances.

In the case of the nanocomposites filled with $0 \mathrm{wt} \% \mathrm{TiO}_{2}$, (Figure 3(a)) many deep holes and voids remained after the fillers were pulled out of the matrix. The presence of these holes means that the interfacial bonding between the $\mathrm{WF}, \mathrm{TiO}_{2}$, and the $\mathrm{PP}$ was weak and therefore the $\mathrm{TiO}_{2}$ could not provide an efficient stress transfer from the matrix. 


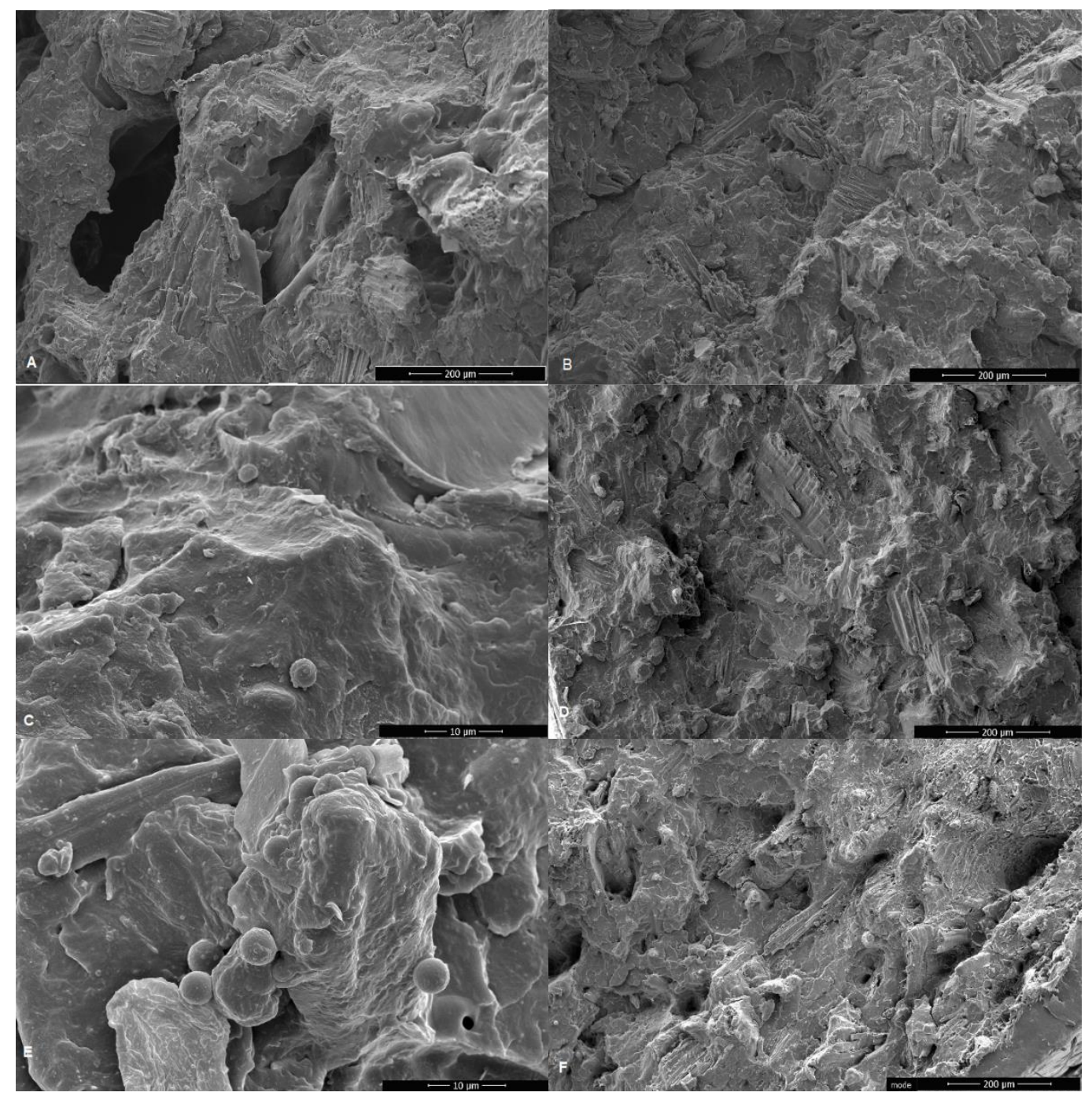

Fig. 3. SEM micrographs of the WPNs with (a) 0 wt $\% \mathrm{TiO}_{2}$, (b) 1 wt $\% \mathrm{TiO}_{2}$, (c) 2 wt $\% \mathrm{TiO}_{2}$, (d) 3 wt $\% \mathrm{TiO}_{2}$, (e) 4 wt $\% \mathrm{TiO}_{2}$, and (f) 5 wt $\% \mathrm{TiO}_{2}$

\section{CONCLUSIONS}

This study examined the effect of $\mathrm{TiO}_{2}$ nanoparticles content on some mechanical, thermal, and surface properties of wood-plastic nanocomposites.

1. The flexural properties and tensile properties of wood polymer nanocomposites increased with increasing amounts of $\mathrm{TiO}_{2}$.

2. Increasing the loading of $\mathrm{TiO}_{2}$ increased the amount of residual ash and thermal stability.

3. The surface roughness of the wood-plastic nanocomposites was reduced by increasing the content of $\mathrm{TiO}_{2}$.

4. The 50/50/5/3 formulation of PP, wood flour, $\mathrm{TiO}_{2}$, and MAPP, respectively, for woodplastic nanocomposites gave the best mechanical, thermal, and surface properties. 


\section{REFERENCES CITED}

Asikuzun, E., and Kaymakci, A. (2018). "Investigation of mechanical behavior of wood polymer nanocomposites (WPNs) samples using static Vickers microhardness tester," Kastamonu University Journal of Forestry Faculty 18(1), 62-74. DOI: 10.17475/kastorman.409185

Ayrilmis, N., Kaymakci, A., and Gulec, T. (2015). "Potential use of decayed wood in production of wood plastic composite," Ind. Crop. Prod. 74, 279-284. DOI: 10.1016/j.indcrop.2015.04.024

Bajwa, S. G., Bajwa D. S., Holt, G., Coffelt, T., and Nakayama, F. (2011). "Properties of thermoplastic composites with cotton and guayule biomass residues as fiber fillers," Ind. Crop. Prod. 33(3), 747-755. DOI: 10.1016/j.indcrop.2011.01.017

Bazant, P., Munster, L., Machovsky, M., Sedlak, J., Pastorek, M., Kozakova, Z., and Kuritka, I. (2014). "Wood flour modified by hierarchical $\mathrm{Ag} / \mathrm{ZnO}$ as potential filler for wood-plastic composites with enhanced surface antibacterial performance," Ind. Crop. Prod. 62, 179-187. DOI: 10.106/j.indcrop.2014.08.028

Beigloo, J. G., Eslam, H. K., Hemmasi, A. H., Bazyar, B., and Ghasemi, I. (2017). "Effect of nanographene on physical, mechanical, and thermal properties and morphology of nanocomposite made of recycled high density polyethylene and wood flour," BioResources 12(1), 1382-1394. DOI: 10.15376/biores.12.1.1382-1394

Chen, H., Wang, M., Lin, Y., Chan, C.-M., and Wu, J. (2007). "Morphology and mechanical property of binary and ternary polypropylene nanocomposites with nanoclay and $\mathrm{CaCO}_{3}$ particles," J. Appl. Polym. Sci. 106(5), 3409-3416. DOI: 10.1002/app. 27017

Deka, B. K., and Maji, T. K. (2011). "Effect of $\mathrm{TiO}_{2}$ and nanoclay on the properties of wood polymer nanocomposite," Compos. Part A-Appl. S. 42(12), 2117-2125. DOI: 10.1016/j.compositesa.2011.09.023

Gan, Y. X. (2009). "Effect of interface structure on mechanical properties of advanced composite materials," Int. J. Mol. Sci. 10(12), 5115-5134. DOI: 10.3390/ijms 10125115

Gardner, D. J., Han, Y., Mayes, D., Pynnonnen, J., and Ruell, S. (2017). "The use of novel modified wood fiber for manufacturing structural wood plastic composite timber for an innovative marine application," in: Wood Modification Research \& Applications, COST action FP1407, Kuchl, Austria.

Ghasemi, I., and Kord, B. (2009). "Long-term water absorption behaviour of polypropylene/wood flour/organoclay hybrid nanocomposite," Iran. Polym. J. 18(9), 683-691.

Hazarika, A., and Maji, T. K. (2013). "Synergistic effect of nano- $\mathrm{TiO}_{2}$ and nanoclay on the ultraviolet degradation and physical properties of wood polymer nanocomposites," Ind. Eng. Chem. Res. 52(38), 13536-13546. DOI: 10.1021/ie401596h

Homkhiew, C., Ratanawilai, T., and Thongruang, W. (2014). "Effects of natural weathering on the properties of recycled polypropylene composites reinforced with rubberwood flour," Ind. Crops Prod. 56, 52-59. DOI: 10.1016/j.indcrop.2014.02.034

ISO 178 (2010). "Plastics - determination of flexural properties," International Organization for Standardization, Geneva, Switzerland.

ISO 527-1 (2012). "Plastics - determination of tensile properties, Part 1 - General principles," International Organization for Standardization, Geneva, Switzerland. 
ISO 4287 (1997). “Geometrical Product Specifications (GPS) - Surface texture: Profile method - Terms, definitions and surface texture parameters," International Organization for Standardization, Geneva, Switzerland.

Kasraei, S., and Azarsina, M. (2012). "Addition of silver nanoparticles reduces the wettability of methacrylate and silorane-based composites," Dent. Mater. J. 26(6), 505-510. DOI: 10.1590/S1806-83242012000600004

Klyosov, A. A. (2007). Wood-plastic Composites, John Wiley \& Sons Publishing, Hoboken, NJ.

Krause, C. A. (2015). "Effect of weathering on the biological aging and durability of wood-polymer composites (WPC)," in: Bringing New Functions to Wood through Surface Modification, COST-STSM-FP1006-21186, pp. 2-9.

Lei, Y., Wu, Q., Clemons, C. M., Yao, F., and Xu, Y. (2007). "Influence of nanoclay on properties of HDPE/wood composites," J. Appl. Polym. Sci. 106(6), 3958-3966. DOI: 10.1002/app. 27048

Liang, K., Shi, S. Q., and Wang, G. (2014). "Effect of impregnated inorganic nanoparticles on the properties of the kenaf bast fibers," Fibers 2(3), 242-254. DOI: 10.3390/fib2030242.

Lin, F. (2006). "Preparation and Characterization of Polymer $\mathrm{TiO}_{2}$ Nanocomposites via in-situ Polymerization," PhD thesis, University of Waterloo, Ontario, Canada.

Nikmatin, S., Syafiuddin, A., Kueh, A. B. H., and Maddu, A. (2017). "Physical, thermal, and mechanical properties of polypropylene composites filled with rattan nanoparticles," J. Appl. Res. Technol. 15(4), 386-395. DOI: 10.1016/j.jart.2017.03.008

Rahman, R., Hamdan, S., and Lai, J. C. H. (2017). "Differential scanning calorimetry (DSC) and thermogravimetric analysis (TGA) of wood polymer nanocomposites," MATEC Web Conf. 87(03013), 1-5. DOI: 10.1051/matecconf/20178703013

Ratanawilai, T., and Taneerat, K. (2018). "Alternative polymeric matrices for woodplastic composites: Effects on mechanical properties and resistance to natural weathering," Constr. Build. Mater. 172, 349-357. DOI:

10.1016/j.conbuildmat.2018.03.266

Saeed, K. H., Park, S. Y., and Ali, N. (2009). "Characterization of poly(butylene terephthalate) electrospun nanofibers containing titanium oxide," Iran. Polym. J. 8(110), 671-677.

Turku, I., Keskisaari, A., Karki, T., Puurtinen, A., and Marttilla, P. (2017). "Characterization of wood plastic composites manufactured from recycled plastic blends," Compos. Struct. 161, 469-476. DOI: 10.1016/j.compstruct.2016.11.073

Turku, I., Karki, T., and Puurtinen, A. (2018). "Durability of wood plastic composites manufactured from recycled plastic," Heliyon 4(3), DOI: 10.1016/j.heliyon.2018.e00559

Zhang, Z.-M., Du, H. Z., Wang, W., and Wang, Q. (2010). "Property changes of woodfiber/HDPE composites colored by iron oxide pigments after accelerated UV weathering," J. Forest. Res, 21, 59-62. DOI: 10.1007/s11676-010-0009-z

Article submitted: October 23, 2018; Peer review completed: January 1, 2019; Revised version received: January 14, 2019; Accepted: January 17, 2019; Published: January 23, 2019.

DOI: 10.15376/biores.14.1.1969-1979 